RASĀYAN J. Chem.

Vol. 13 | No. 3 |1478-1485| July - September | 2020 ISSN: 0974-1496 | e-ISSN: 0976-0083 | CODEN: RJCABP

\title{
Bio-Friendly Synthesis of Silver Nanoparticles Using Mangrove Rhizophora stylosa Leaf Aqueous Extract and Its Antibacterial and Antioxidant Activity
}

\author{
Nancy Willian ${ }^{1,2}$, Syukri $^{1}$, Zulhadjri $^{1}$, Arniati Labanni ${ }^{1}$, Syukri Arief ${ }^{1 *}$ \\ ${ }^{1}$ Department of Chemistry, Faculty of Mathematics and Natural Sciences, University of \\ Andalas, Kampus Limau Manis, Padang 25163, West Sumatera-Indonesia \\ ${ }^{2}$ Department of Chemistry Education, Faculty of Teaching and Education, Raja Ali Haji \\ Maritime University, Tanjungpinang, Riau Archipilago-Indonesia \\ *E-mail : syukriarief@sci.unand.ac.id
}

\begin{abstract}
Plant mediated biosynthesis of nanoparticles is going important due to simple processes and non-toxic materials utilization. Rhizophora stylosa (RS) mangrove leaf extract was successfully used as a bioreductor in the production of AgNPs by varying the concentration of silver nitrate and the amount of extract. Leaf extract is made by dissolving 10 grams of dried leaf powder in $100 \mathrm{ml}$ double-distilled water (DDW). The concentration of silver nitrate was variable by $1,5,10 \mathrm{mM}$ with different amounts of leaf extract. The UV-Vis absorption spectrum of colloid in the range between 439-453 nm confirmed that AgNPs have been successfully synthesized. FT-IR absorption band shows the feasible biomolecules of Rhizophora stylosa responsible for the production of silver nanoparticles were amine, alcohol, phenol, alkyl halide, and aromatic combinations groups. The XRD pattern regulates that the synthesized AgNPs were in a face-centered cubic (fcc) crystal structure with an average size of $25 \mathrm{~nm}$. TEM images informed that the synthesized AgNPs have a spherical shape with a size range between 9 to $57 \mathrm{~nm}$. The average size of the nanoparticles was $30 \mathrm{~nm}$. The solution of stable silver nanoparticle colloid from 1 until 3-month incubation. AgNPs have good antibacterial and antioxidant activity compared to pure plant extract.
\end{abstract}

Keywords: Green Synthesis, Silver Nanoparticles, Rhizophora stylosa, Antibacterial, Antioxidant

(C) RASĀYAN. All rights reserved

\section{INTRODUCTION}

Nanotechnology is one of the essential parts in the synthesis of nanoparticles (NP) with dimensions of 1$100 \mathrm{~nm}$. The atoms of nanoparticles are more concentrated on the surface than those of microparticles, which increases their functional ability ${ }^{1}$. They have excellent properties such as large surface area, structural properties, and long shelf life. Nanomaterial properties have the potential for disease diagnosis. Plant mediated synthesis called biosynthesis provides a more effective technique than physical and chemical methods. The main advantages of biosynthesis are not using toxic chemicals, temperature, energy, and high pressure during nanoparticle synthesis ${ }^{2}$. Biological methods as a safe, clean, and environmentally friendly synthesis can be established for large-scale production ${ }^{3}$. Silver nanoparticles exhibit very high potential in biological applications, especially as an antibacterial and antioxidant agent. Mangrove plants, as traditional medicinal plants, have been widely used by coastal communities ${ }^{4}$. Rhizophora genus has been used traditionally as a source of dyes and medicines, especially bark ${ }^{5}$. It also has been investigated as antibacterial and antioxidant activity due to the content of flavonol derivatives, mainly catechin, and epicatechin. This mangrove Rhizophora stylosa can be found along the coast of Riau Archipelago, Indonesia. Leaf extracts of mangrove plants act as capping and reducing agents as well, which are responsible for crystal growth, hence determine the nature of silver nanoparticles ${ }^{6}$. There are very few mangrove species investigated for antimicrobial and antioxidant compounds and need to be explored further ${ }^{7}$. It is recommended to use a renewable source of mangrove plants from natural products combined with AgNPs as an antibacterial and antioxidant agent. In this study, the secondary metabolic

Rasayan J. Chem., 13(3), 1478-1485(2020)

http://dx.doi.org/10.31788/ RJC.2020.1335760

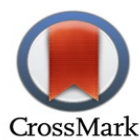


RASĀYAN J. Chem.

Vol. 13 | No. 3 |1478-1485| July - September | 2020

components in mangrove extract such as flavonoids are expected to reduce $\mathrm{Ag}^{+}$to $\mathrm{Ag}^{0}$ and act as a capping agent at once to stabilize it. Hence, any additional reducing agent was not necessary. This study aims to determine the ability of mangrove Rhizophora stylosa (RS) leaf extract in synthesizing and determining the characteristics of silver nanoparticles, such as particle size, crystal structure, and stability. The parameters in this study such as the concentration of the precursor and the amount of extract were variated. Besides, the inhibitory effect of bioactive compounds derived from mangroves required further investigation as an antimicrobial agent against bacterial infections and their antioxidant activity. This is a first and novel report on biosynthesis silver nanoparticles synthesis using aqueous leaf extract of RS as a reducing agent.

\section{Collection of Plant Material}

\section{EXPERIMENTAL}

Leaves of RS mangrove were collected from mangrove forest Tanjungpinang, Riau Archipelago, Indonesia. Firstly, the leaves were washed thoroughly with running tap water to remove mud particles that might stick and affect the final result. The clean leaves were then shade dried for 15 days and turned into a fine powder. RS leaf was identified in the Laboratory of the marine science department, Faculty of marine science of fisheries Maritim Raja Ali Haji University Tanjungpinang, with a specified number of $0101 / 2018$.

\section{Preparation of the Mangrove Aqueous Extract and Biosynthesis of Silver Nanoparticles}

The 10 grams of dried fine powder of RS leaf is mixed with $100 \mathrm{ml}$ of double-distilled water (DDW) and heated for 1 hour at $65{ }^{\circ} \mathrm{C}$ and then filtered using Whatman paper No. 1. The extract was placed in a sealed bottle at a temperature of $4{ }^{\circ} \mathrm{C}$ for further use. Preparation of AgNP nanoparticles using RS leaf extract was conducted based on approved procedures by P. Thatoi, et al. ${ }^{8}$ The concentration of silver nitrate was variated by 1,5 , and $10 \mathrm{mM}$ in order to. The objective of using 3 concentration of $\mathrm{AgNO}_{3}$ was to optimize the metal concentration, which would be the most productive optimum for the smallest size of AgNPs. In this study, several different amounts of leaf extract $(1,2$, and $3 \% \mathrm{v} / \mathrm{v})$ were used to study the effect of plant extract amount on the properties of AgNPs. Also, the relation between reaction time and stability of silver nanoparticles was studied. The Silver solution was added to a different amount of mangrove leaf extracts. The reaction mixture is allowed to stand at room temperature for up to 3 months, and the absorbance of the sample was monitored rhythmically using a UV-Vis spectrophotometer.

\section{Phytochemical Activity}

Qualitative phytochemical analysis of RS leaf extract was carried out using the methodology described by R. Bhuvaneswari, et al. ${ }^{6}$ by testing the alkaloid, flavonoid, phenolic, triterpene, saponin, and tannin components. The results of this test are stated qualitatively as positive (+) or negative (-), which are described in tabular form.

\section{The Characterization of Silver Nanoparticles}

UV-Vis absorption spectra of colloidal AgNPs ( $1 \mathrm{ml}$ sample diluted in $10 \mathrm{ml}$ deionized water) was monitored using UV-Vis Spectrophotometer (Shimadzu-1800) in the wavelength range between 200-800 $\mathrm{nm}$ after a reaction time of $0 ; 0.5 ; 1 ; 2 ; 4 ; 6 ; 24 ; 168$ hours, and $1-3$ month. The absorbance of the samples was then continuously measured up to incubation time of 3 months. To obtain powder for further analysis, colloidal silver nanoparticles were prepared by increasing the concentration of all reagents up to 10 times. The precipitated AgNPs ware separated by the supernatant, then ware washed with distilled water and dried in the oven in temperature of $110^{\circ} \mathrm{C}$ to obtain a dry powder. X-ray diffraction (Philips Xpert powder PAN Analytical) analysis was conducted to study the crystallinity of the prepared AgNPs. The crystalline size was calculated using the Scherrer's formula $(D=K \lambda / \beta \cos \theta)$. The morphology, size distribution, and shape of AgNPs were determined using TEM (JEOL JEM 1400). Fourier Transform Infra-Red Spectroscopy (FT-IR, Perkin-Elmer) was used to examine the functional group contained in the bioactive compounds of RS leaf extract, which could be responsible for the formation of nanoparticles.

\section{Antibacterial Activity}

Antibacterial activity was measured by the agar diffusion method to measure the efficacy of RS leaf extract ${ }^{9}$. Antibacterial activity tests ware carried out against Staphylococcus aureus (S. aureus) and 
RASĀYAN J. Chem.

Vol. 13 | No. 3 |1478-1485| July - September | 2020

Escherichia coli (E. coli) bacteria with positive control of amoxicillin. This methodology refers to a previous study ${ }^{10}$. Some of the two grams of nutrient agar NA (Merck) boiling in $100 \mathrm{~mL}$ aquadest, homogeneous media is sterilized at $121{ }^{\circ} \mathrm{C}$ in 15 minutes. Both bacteria were grown in NA and allowed for $24 \mathrm{~h}$. Sterile cotton with AgNPs sample (various concentrations) was placed on well. All the media were left at room temperature for $18-24$ hours at $37^{\circ} \mathrm{C}$ to measure the inhibition zone (mm). The test was conducted in duplicate.

\section{Antioxidant Activity}

Antioxidant activity of the sample was characterized determined using 1,1-diphenyl-2-picrylhy-drazyl hydrate (DPPH, Merck). Silver nanoparticles were screened for DPPH free radical scavenging activity method as described by P Thatoi ${ }^{8}$, with minor modification. Briefly, $3.8 \mathrm{ml}$ of $30 \mu \mathrm{g} / \mathrm{mL}$ DPPH was mixed with $0.2 \mathrm{~mL}$ different concentrations of $30-70 \mu \mathrm{g} / \mathrm{ml}$ of silver nanoparticles then was incubated in the dark for 30 minutes. The absorbance of the samples was determined by Spectrophotometer UV-Vis at $517 \mathrm{~nm}$. DPPH in methanol without sample was used as a control, and Vitamin C was used as standard. The antioxidant activity the leaf extract was also tested as a control. All measurements were repeated in triplicates. Antioxidant activity was estimated by calculating the percentage of free radical scavenging by the formula. The $\mathrm{IC}_{50}$ value was defined as the minimum antioxidant required to scavenge $50 \%$ of the DPPH free radicals.

\section{RESULTS AND DISCUSSION \\ Phytochemical analysis of Rhizophora stylosa Leaf Extracts}

The leaf extract of RS was simply extracted using double-distilled water, which showed a positive test result for the content of some bioactive compounds. The result of phytochemicals analysis (Table-1) suggests the presence of steroid, triterpenoid, flavonoid, and polyphenol in the RS leaf extract. These secondary metabolite groups are expected to reduce $\mathrm{Ag}^{+}$to $\mathrm{Ag}^{0}$. A Similar active compound was also found in the species of Rhizophora Lamarckii ${ }^{11}$, Avicenna Marina $^{3}$, and Sargassum Muticum. ${ }^{12}$

Table 1-: Phytochemical Analysis of RS Leaf Extracts

\begin{tabular}{c|c}
\hline $\begin{array}{c}\text { Types of Secondary } \\
\text { Metabolites }\end{array}$ & Aquabidestilat Water \\
\hline Alkaloid & - \\
\hline Steroid & + \\
\hline Triterpenoid & + \\
\hline Flavonoid & + \\
\hline Saponin & - \\
\hline Polyphenol/ tannin & + \\
\hline
\end{tabular}

$+:$ Present $\quad-:$ Not present

Based on previous research, reported that 7 flavanol derivatives including epicatechin and catechin, cinchonain 1b, 3.7-O-diacetyl(-) epicatechin, and 3-O-acetyl(-)-epicatechin were isolated from steam and twigs of the mangrove plant Rhizophora stylosa ${ }^{13}$.

\section{Biosynthesis of AgNPs}

A detailed characterization study on AgNPs extracellular biosynthesis using variations in the quantity of mangrove leaf extract was carried out. When mangrove leaf extract (with a concentration of $1,2,3 \% \mathrm{v} / \mathrm{v}$ ) could react with a solution of silver nitrate $(1,5$, and 10) $\mathrm{mM}$ with a total volume of $50 \mathrm{ml}$ synthesis solution. Briefly the samples were coded as AgNPs-A-1-1, AgNPs-A-5-1, and AgNPs-A-10-1 which means silver nanoparticles with a precursor concentration of $(1,5$ and 10$) \mathrm{mM}$ and extract concentration of $1 \%$ also for 2 dan $3 \%$ extract. After mixture, the color turned to pale yellow and dark brown, which shows a gradual reduction of $\mathrm{AgNO}_{3}$ by leaf extract. This color change pattern is due to surface plasmon resonance excitation (SPR) in AgNPs ${ }^{11}$. 
RASĀYAN J. Chem.

Vol. 13 | No. 3 |1478-1485| July - September | 2020

\section{UV-Vis Spectrum in the Formation of Silver Nanoparticles}

Figure-1 shows the UV-Vis colloidal silver spectra obtained at different leaf extract concentrations. UVVis spectrophotometer analysis spectrum shows that the use of high concentration leaf extract resulted in sharper absorbance peak, which might be due to the higher number of biomolecules involved in the reduction reaction. Leaf extract concentration of $3 \%$, more easily agglomerated during the incubation period of more than 1 month, this is also supported by the SPR peak, which shifts to redshift and larger particle size (UV-VIs image not showed). This happens because the excess reductant is not proportional to the amount of $\mathrm{Ag}^{+}$solution in the reduction process. The position of the peak of the plasmon depends on the size and shape of the particles ${ }^{1,14}$. Figure 1 shows the optimal silver nanoparticles concentration and extract for nanoparticle synthesis ( AgNPs-A-1-1, AgNPs A-5-2, AgNPs-A-10-1)

The maximum absorption peak for nanoparticles synthesized using precursor concentration of 1,5 , and $10 \mathrm{mM}$ were in wavelength of 439,448 , and $453 \mathrm{~nm}$, respectively. Figure 1 shows that as time increases, the absorption of the solution increases. Previous research also revealed that the absorbance in a wavelength range of 420-450 nm was associated with AgNPs with a size range varied between 2-100 nm with spherical shape ${ }^{15}$. The spectrum showed a shift towards the redshift or blue shift related to particle size, shape, state of aggregation, and surrounding dielectric media ${ }^{14}$. The stability of silver to nanoparticle colloids was observed for up to 3 months. Nanoparticles with a concentration of $1 \mathrm{mM}$ and $5 \mathrm{mM}$ are more stable than the concentration of $10 \mathrm{mM}$. This happens because the higher the concentration, the faster the agglomeration occurs, causing reduced nanoparticle uptake. Thus, UV-visible spectroscopy is an advisable method for the initial indicator of nanoparticle manufacturing with a spherical shape, which will be clarified further in the TEM analysis.

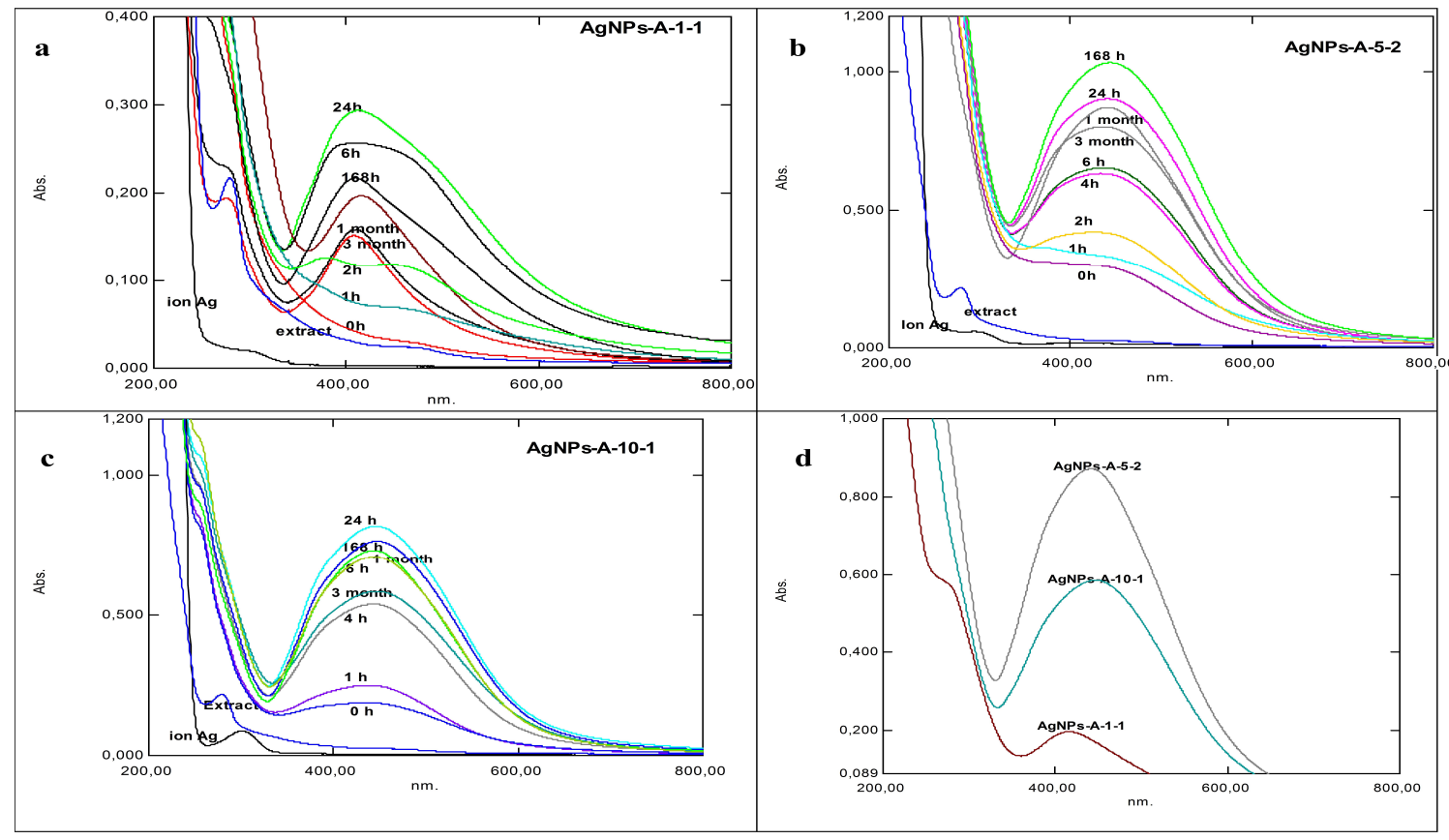

Fig.-1: (a,b,c) UV-Visible Absorbance Spectra of AgNPs at (1, 5, and 10) mM with Extract Added and (d) Stability

\section{Fourier Transforms Infrared Spectroscopy (FTIR)} of Nanoparticles for 3 month

This uptake of RS dry powder extract showed a typical uptake role of the hydroxyl (OH-) group with a broad and strong band at $3302.81 \mathrm{~cm}^{-1}$ referred to alcoholic, phenolic and flavonoid groups which act as capping agents on the surface of the nanoparticles. The FTIR spectra of RS dry powder showed a typical peak of the hydroxyl $(-\mathrm{OH})$ group with a broad and strong band at $3302.81 \mathrm{~cm}^{-1}$. While the absorption bands of $808.08 \mathrm{~cm}-1$ and $657.04 \mathrm{~cm}-1$ showed that various phytochemicals were presented in leaf extract, which acted as capping agents. The peak at $1051 \mathrm{~cm}^{-1}$ (CO stretch of the alcoholic group) in the 
RASĀYAN J. Chem.

Vol. 13 | No. 3 |1478-1485| July - September | 2020

extract was shifted to a lower wavenumber of $1270.57 \mathrm{~cm}^{-1}(\mathrm{CN}$ stretching band of the aromatic amine group). It might be due to the reduction of silver ion to silver nanoparticles by carboxyl groups and amine groups as a stabilizer on the surface of nanoparticles ${ }^{16}$. The shifting of wavenumber in leaf extract and AgNPs suggested that there is an interaction between functional groups contained in biomolecules of leaf extract and silver cation due to the oxidation and reduction process of silver nanoparticles ${ }^{11}$. This evidence suggests that biological molecules can be utilized in the formation and stabilization of colloidal silver nanoparticles in aqueous media to control the size and prevent agglomeration ${ }^{16}$.

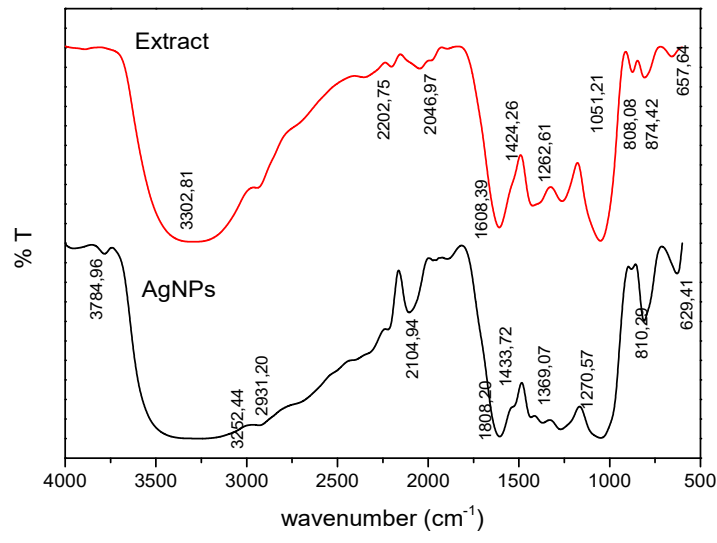

(a)

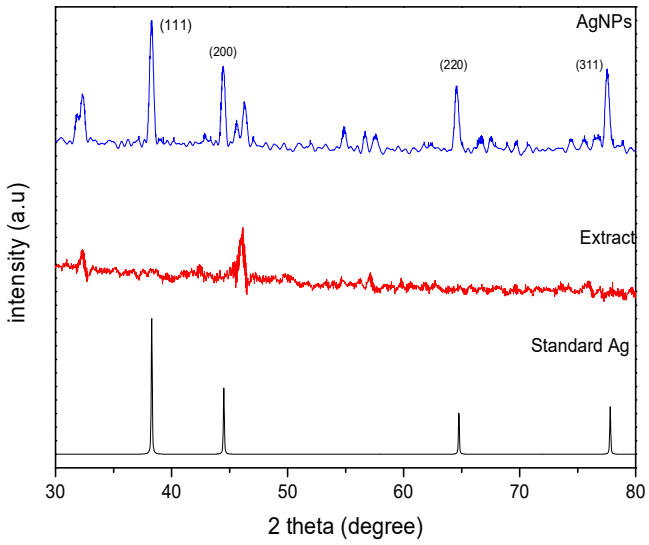

(b)

Fig.-2: FTIR Spectra Extract of (a) RS Extract and RS-AgNPs, (b)XRD Pattern of the RS-AgNPs Synthesized RS Extract and Ag Standard.

\section{XRD (X-Ray Diffraction)}

The structural determination of RS-AgNPs was characterized using XRD analysis. The diffraction pattern is shown in Fig.-2b. The peaks observed at $2 \theta$ values of $38.27^{\circ}, 44.45^{\circ}, 64.56^{\circ}$ and $77.53^{\circ}$ with a facecentered cubic (FCC) structure of silver (ICSD N0 4068). Also, a peak in $2 \theta$ of about $46.05^{\circ}$ degrees is observed, which attributed to RS extract, and confirmed the presence of a stabilizing agent in AgNPs sample, as reported by K. Mallikarjuna, et al. $(2012)^{17}$. Similar observations are also reported by Ramayana et al. (2019) that the extract plays a role in reducing, capping, and maintaining particle size ${ }^{18}$. The crystal size of the silver nanoparticles formed in the reaction was found to be $25-32 \mathrm{~nm}$, based on Scherrer equation.

\section{Transmission Electron Microscopy (TEM)}

TEM images (Fig.-3) reveal that the synthesized AgNPs have a spherical shape with a size range between 9 to $57 \mathrm{~nm}$. The distribution size histogram shows that the particles most often are in the range of $29 \mathrm{~nm}$, and the average size of nanoparticles is $30 \pm 2 \mathrm{~nm}$ was calculated by "image J" software. The previous biosynthesis of AgNPs using mangrove plant has reported the average particles size $71-110 \mathrm{~nm}$ using Avicenna marina ${ }^{3}$ and Exoecaria agallocha in range $23-42 \mathrm{~nm}^{19}$. Under careful observation, as seen in Fig.-3b. The edge of the nanoparticle is brighter than the center of the nanoparticle. Silver nanoparticles are surrounded by a thin layer that shows that these particles are encapsulated by biomolecules such as proteins and other secondary metabolites in RS extract.

\section{Antibacterial Activity}

The use of medicinal plants such as gambir ${ }^{20}$ and mangrove leaf ${ }^{21}$ is an alternative bioreducing agent in synthesizing metal nanoparticles. The antibacterial activity of mangroves such as Rhizophora Mucranata, have been reported ${ }^{22}$. The solution tested is colloidal, which is stable for up to 1 month. The antibacterial activity was carried out using a good diffusion method against $S$. aureus and E. coli with amoxicillin as positive control and distilled water as a negative control. 
RASĀYAN J. Chem.

Vol. 13 | No. 3 |1478-1485| July - September | 2020
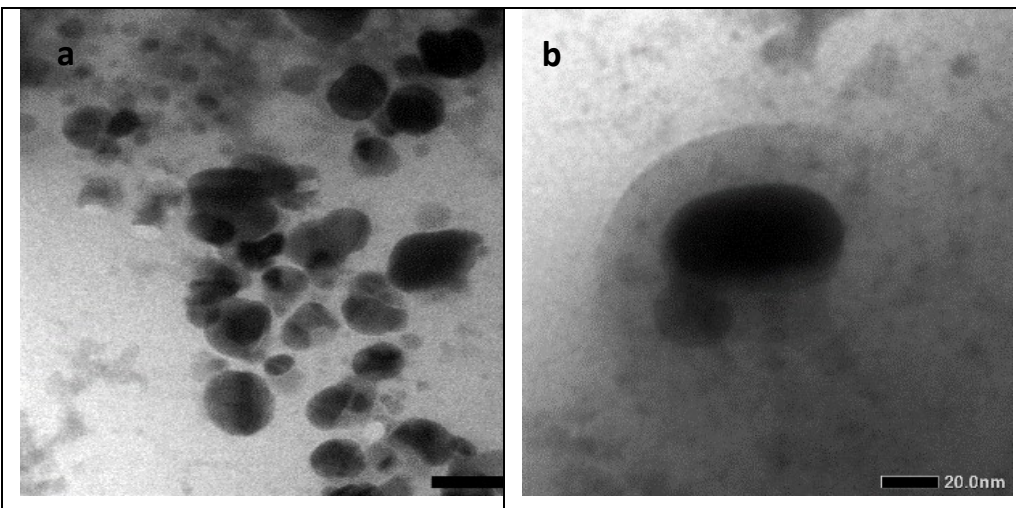

C

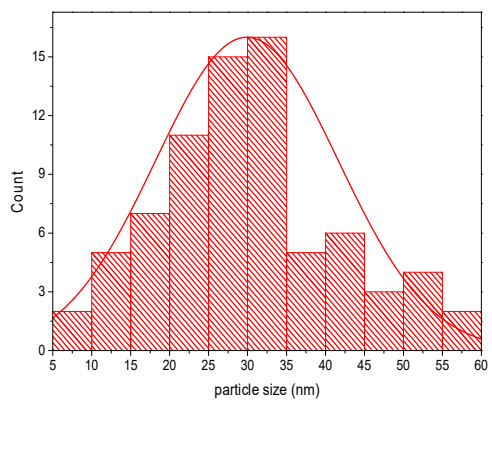

Fig.-3: TEM Image of Silver Nanoparticle 1mM in Two magnifications (a) 50nm, (b) $20 \mathrm{~nm}$, (c) Histogram Distribution Particle Size.

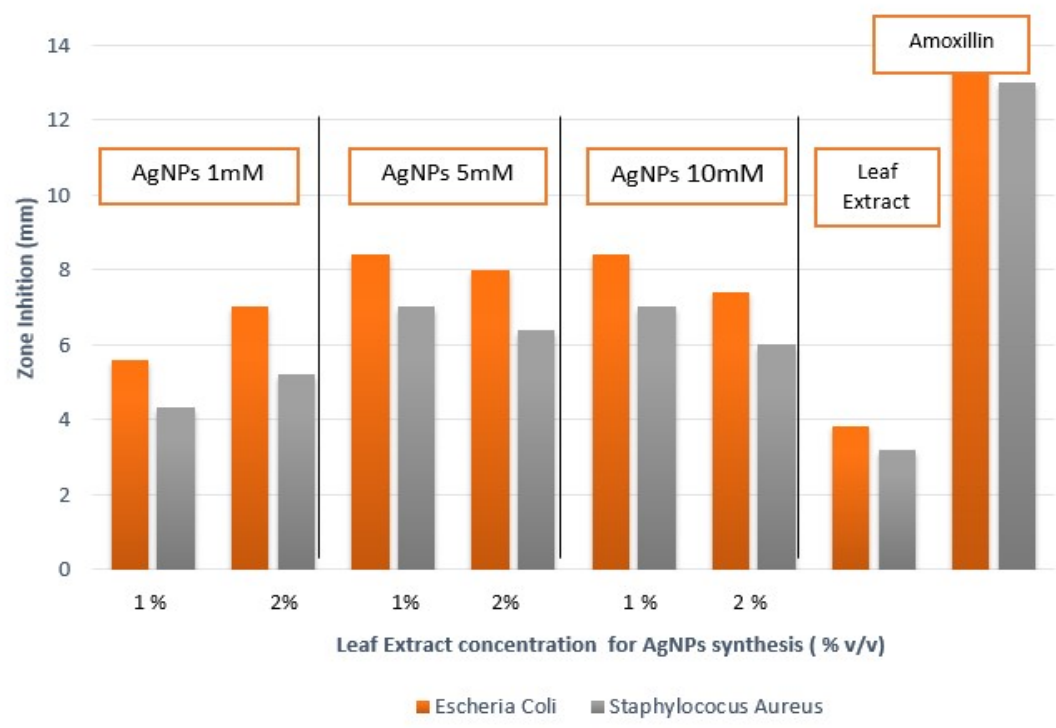

Fig.-4: Inhibition Zone of RS-AgNPs with Different Extract Concentration.

Figure-4 shows the result of the antibacterial activity test of AgNPs synthesized with precursor concentration of 1,5 , and $10 \mathrm{mM}$ based on the inhibition zone. All samples showed higher activity against $E$. coli than those against $S$. aureus. This might be due to the different thickness of the cell was of the bacteria, where gram-negative bacteria have a thinner cell wall than those of gram-positive bacteria. ${ }^{23,24}$ The AgNPs using 5 and $10 \mathrm{mM}$ concentration of precursor showed higher activity than AgNps prepared using $1 \mathrm{mM}$. Although there was no significant difference between samples with 5 and $10 \mathrm{mM}$, these results showed that the concentration of precursor affects the antibacterial activity of AgNPs.

Under certain conditions, agglomeration with the amount of extract and certain silver concentrations affect antibacterial activity. However, the result showed that as-synthesized AgNPs showed higher antibacterial activity than AgNPs previously report by Mouafi et al. $(2014)^{25}$, who synthesized AgNPs using Rhizopora stylosa extracted using ethyl acetate. The antibacterial activity of AgNPs might occur due to the binding between nanoparticles microorganism membranes through electrostatic interactions, disruption of cell walls, and influencing intracellular processes such as DNA, RNA, and synthesis of proteins. Based on these results, it can be concluded that AgNPs have the potential to be developed as antibacterial agents. 
RASĀYAN J. Chem.

Vol. 13 | No. 3 |1478-1485| July - September | 2020

\section{Antioxidant Activity}

Table-2 shows the result of the antioxidant activity test of AgNPs synthesized using precursor concentrations of $1,5,10 \mathrm{mM}$ with $2 \%$ extract, based on $\mathrm{IC}_{50}$ values. The percentage of inhibition was determined by comparing the absorbance of pure DPPH to the absorbance of tested AgNPs at a wavelength of $517 \mathrm{~nm}$. The lower the value of $\mathrm{IC}_{50}$, the more toxic the nanoparticles. It is assumed that the DPPH free radical scavenging activity of silver nanoparticles mediated by RS marine plants is related to the content of the hydroxyl group. Compounds that have adjacent hydroxyl groups on the B-ring have higher activity as reported by (Li et al., 2007) ${ }^{13}$. From the above data, it can be concluded that the main component responsible for the antioxidant activity of the RS extract is a flavanol derivative due to the content of phenolics, flavonoids and polysaccharides.

\begin{tabular}{|c|c|}
\hline Samples & $\mathrm{IC}_{50} \mathrm{DPPH}(\mu \mathrm{g} / \mathrm{ml})$ \\
\hline AgNPs-A-1-2 & $50.62 \pm 0.46$ \\
\hline AgNPs-A-5-2 & $48.34 \pm 0.20$ \\
\hline AgNPs-A-10-2 & $44.09 \pm 0.39$ \\
\hline Leaf Extract & $53.77 \pm 0.60$ \\
\hline Ascorbic Acid & $23.67 \pm 0.39$ \\
\hline
\end{tabular}

\section{CONCLUSION}

Bio-Friendly synthesis of AgNPs using an aqueous extract of Rhizophora stylosa has been successfully conducted where the extract acted as fast, reliable, and nontoxic stabilizer, reducing agent, and capping agent. The resulting AgNPs are stable for three months for $1 \mathrm{mM}$ and $5 \mathrm{mM}$ concentration. These nanoparticles have the potential to be used in biomedical applications.

\section{ACKNOWLEDGMENT}

This research work was supported by The Indonesian Endowment Fund For Education (LPDP) of Ministry of Finance Indonesia under Grand No. 201710210211848.

\section{REFERENCES}

1. P.Singh, Y. J. Kim, H. Singh, R. Mathiyalagan, C. Wang, and D. C. Yang, Journal of Nanomaterials, 2015, 10(2015), DOI:10.1155/2015/234741

2. G.M. Srirangam, K. P. Rao, Rasayan Journal of Chemistry, 10(1), 46(2017), DOI: 10.7324/RJC.2017.1011548

3. M. Gnanadesigan, M. Anand, S. Ravikumar, M. Maruthupandy, M. Syed Ali, V. Vijayakumar, and A. K. Kumaraguru, Applied Nanoscience, 2, 143(2012), DOI:10.1007/s13204-011-0048-6

4. K. S. B. Naidu, N. Murugan, J. K. Adam, Sershen, BioNanoScience, 9, 226(2019), DOI: 10.1007/s12668-019-00612-4

5. G. Franci, A. Falanga, S. Galdiero, L. Palomba, M. Rai, G. Morelli, and M. Galdiero, Molecules, 20, 8856(2015), DOI: 10.3390/molecules20058856

6. M. A. R. Bhuvaneswari, R. J. Xavier, and M. Arumugam, Karbala International Journal of Modern Science, 1(2), 129(2015), DOI:10.1016/j.kijoms.2015.08.003

7. N. L. Dahibhate, A. A. Saddhe, and K. Kumar, The Natural Products Nournal, 9 (2), 86(2019), DOI: $10.2174 / 2210315508666180910125328$

8. P.Thatoi, R. G. Kerry, S. Gouda and J. K. Patra, Photochemisty and Photobiology, 163, 311(2016), DOI: 10.1016/j.jphotobiol.2016.07.029

9. C.T Handoko, A. huda, M.D Bustan, B. Yudono and F Gulo, Rasayan Journal of Chemistry, 10(4), 1137(2017), DOI: 10.7324/RJC.2017.1041875

10. A. Labanni, Z. Zulhadjri, D. Handayani, Y. Ohya, and S. Arief, Journal of Dispersion Science and Technology, 0, 1 (2019), DOI:10.1080/01932691.2019.1626249 
RASĀYAN J. Chem.

Vol. 13 | No. 3 |1478-1485| July - September | 2020

11. S. D. Kumar, G. Singaravelu, S. Ajithkumar, K. Murugan, M. Nicoletti and G. Benelli, Journal Cluster Science, 28, 359(2017), DOI:10.1007/s10876-016-1100-1

12. S. Azizi, F. Namvar, M. Mahdavi, M. Bin Ahmad, and R. Mohamad, Materials, 6(12), 5942(2013), DOI: $10.3390 / \mathrm{ma} 6125942$

13. D. L. Li, X. M. Li, Z. Y. Peng and B. G. Wang, Molecules, 12, 1163 (2007), DOI:10.3390/12051163

14. H. Schwegmann, A. J. Feitz, and F. H. Frimmel, Journal Colloid Interface Science, 347(1) 43 (2010), DOI: $10.1016 /$ j.jcis.2010.02.028

15. S. Rajeshkumar and L. V. Bharath, Chemico Biological Interaction. 273, 219(2017), DOI: $10.1016 /$ j.cbi.2017.06.019

16. S. Ahmad, S. Munir, N. Zeb, A. Ullah, B. Khan, J. Ali, International Journal of Nanomedicine, 14, 5087 (2019), DOI: $10.2147 /$ IJN.S200254

17. K. Mallikarjuna, N. John Sushma, G. Narasimha, L. Manoj, and B. Deva Prasad Raju, Arabian Journal of Chemistry, 7, 1099 (2012), DOI:10.1016/j.arabjc.2012.04.001

18. R. Ramanarayanan, N. Chokiveetil, N. Pullanjiyot, B. Ninnora Meethal and S. Swaminathan, Material Research Bulletin, 114, 28 (2019), DOI:10.1016/j.materresbull.2019.02.017

19. R. Bhuvaneswari, R.John Xavier and M. Arumugam. Journal Parasitic Disease, 41, 180(2016), DOI: 10.1007/s12639-016-0773-6

20. S. Arief, V. Gustia, D. Vanda, and T. Ban, Journal of Chemical and Pharmaceutical Research, 7(9S), 189 (2015)

21. R. S. Chinnappan, K. Kandasamy and A. Sekar, African Journal Biotechnology, 14(8), 1525(2015), DOI: $10.5897 / a j b 2015.14527$

22. J. Umashankari, D. Inbakandan, T. T. Ajithkumar and T. Balasubramanian, Aquatic Biosystems, 8(11), 1(2012), DOI:10.1186/2046-9063-8-11

23. Y.N. Slavin, J. Asnin, U.O.Häfeli and H. Bach, Journal of Nanobiotechnology, 15(65), 1(2017), DOI: $10.1186 / \mathrm{s} 12952-017-0308-\mathrm{z}$

24. E.P.Ortiz, J.H.R Ruiz,E.M.H Marquez, J.L.Esparza, A.D Cornejo,J.C.C Gonzalez, L.F.E Cristobal and S.Y.R Lopez, Journal Of nanomaterials, 2017, 9 (2017), DOI:10.1155/2017/4752314

25. F. E. Mouafi, S. M. Abdel-Aziz, A. A. Bashir and A. A. Fyiad, World Applied Science Journal, 29(4), 547 (2014), DOI: 10.5829/idosi.wasj.2014.29.04.13901

[RJC-5760/2020] 